\title{
Experimental Investigation of Aerodynamic Characteristics for Three Typical Micro Wind Turbines at Low Reynolds Number
}

\author{
J. Y. Zhu ${ }^{1,2 \dagger}$, L. Zhang ${ }^{3}$, Q. L. Qu² and P. Q. Liu $^{2}$ \\ ${ }^{1}$ College of Aeroengine, Shenyang Aerospace University, Shenyang, Liaoning Province, 110136, China \\ ${ }^{2}$ Key Laboratory of Fluid Mechanics, Ministry of Education, Beihang University, Beijing, 100083, China \\ ${ }^{3}$ Shenyang Academy of Environmental Sciences, Shenyang, Liaoning Province, 110167, China \\ †Corresponding Author Email: michellend@126.com
}

(Received June 18, 2019; accepted December 2, 2019)

\begin{abstract}
Onsite utilization of wind energy in the urban environment is an effective solution to environmental protection and energy security. The typically micro wind turbines, including Savonius vertical axis wind turbine, H-type vertical axis wind turbine and micro horizontal axis wind turbine are more suitable for distributed generation, relative to centralized generation of large scale wind turbines. However, the wind in the urban environment characterized by low wind speed, high levels of turbulence and strongly unsteady direction and speed, directly affecting the aerodynamic characteristics of wind turbine. In the present work, wind tunnel tests have been conducted to investigate the low Reynolds number effect on aerodynamic characteristics for these three typical micro wind turbines, and the aerodynamic differences among them have been compared qualitatively and quantitatively. The experimental results show that micro horizontal axis wind turbine and H-type vertical axis wind turbine, belonging to lift-type wind turbine, have relatively higher startup wind speed and lower power coefficient due to deteriorative aerodynamic performance of airfoil at low wind speed. However, Savonius vertical axis wind turbine, as a drag-type wind turbine, exhibits excellent aerodynamic performance at low Reynolds number. The Savonius wind turbine has apparent output power at $5 \mathrm{~m} / \mathrm{s}$, and the peak power coefficient exceeding 0.2 at $9 \mathrm{~m} / \mathrm{s}$ being superior to that of two other lift-type wind turbines at the same wind speed. In addition, in consideration of natural advantage of vertical axis wind turbine, Savonius wind turbine is the best option for applying at low Reynolds number urban environment.
\end{abstract}

Keywords: Wind energy; Small wind turbine; Aerodynamic characteristics; Low Reynolds number; Wind tunnel test.

\section{INTRODUCTION}

With industrialization and urbanization development, the energy demand in cities is soaring up. Onsite utilization of wind energy in the urban environment is an effective way to alleviate the energy crisis (Mertens 2002; Dayan 2006). The conventional large scale wind turbine in rural areas has excellent aerodynamic performance with the power coefficient more than 0.4 , however, micro wind turbine is apparently more suitable for distributed generation in urban environment, due to relatively smaller size. Micro wind turbine is usually defined with the rated power less than $2.5 \mathrm{~kW}$ (Peacock et al. 2008) or the rotation diameter less than 1.25m (Gipe 1999), of which the design wind speed is between $3 \mathrm{~m} / \mathrm{s}$ to $15 \mathrm{~m} / \mathrm{s}$, and the alternative types of which include small horizontal axis wind turbine (HAWT), H-type vertical axis wind turbine $(\mathrm{H}-\mathrm{VAWT})$ and Savonius vertical axis wind
turbine(S-VAWT). The aerodynamic characteristics in urban areas is obviously different from that in the open rural areas, which is characterized by low average wind speed, high level of turbulence intensity and time-varying wind speed and wind direction (Ledo et al. 2011), therefore, the micro wind turbines are subject to low Reynolds number, high turbulence intensity and strong unsteadiness of wind, the low Reynolds number effect becomes even more apparently in consideration of smaller size of the wind turbines. The Reynolds number order for micro wind turbine is limited to $10^{4}$ or $10^{5}$, less than that for conventional large wind turbine, necessarily resulting in degradation of aerodynamic performance.

There have lots of studies on aerodynamic characteristics of micro wind turbine numerically and experimentally. The HAVT and H-VAWT are both lift type wind turbines, of which aerodynamic 
performance rely on the aerodynamic characteristics of airfoil. Karthikeyan et al. (2015) reviewed the aerodynamic development on small HAWT, pointing that design of low Reynolds number airfoil contributed to improve the aerodynamic performance of wind turbine. Driss et al. (2013) pointed out that under the same tip speed ratio, the power coefficient of micro HAWT increased with Reynolds number, but the static torque coefficient would not change. Zhu et al. (2018) studied the effect of Reynolds number and blade pitch angle on a 2blade micro HAWT and found that peak power coefficient and its corresponding tip speed ratio increased and decreased with the increase of Reynolds number, respectively. Bhutta et al. (2012) reviewed various configurations and design techniques of micro H-VAWT without considering the Reynolds number effect. Somoano et al. (2018) investigated the effect of Reynolds number and blade pitch on performance for a three straight bladed VAWT, the peak power coefficient increased with Reynolds number ranging from $3 \times 10^{5}$ to $5 \times 10^{5}$. SVAWT is the drag type wind turbine, having an distinct advantage in self-startup. Kang et al. (2014) and Zemamou et al. (2017) reviewed the development of micro S-VAWT with emphasis on aerodynamic profiles and fluid dynamic aspects, respectively. The reviews of Akwa et al. (2012) and Roy et al. (2013) involved Reynolds number effect on the micro S-VAWT, it was found that the increase of Reynolds number delayed the boundary layer separation on the convex side of the buckets of the SVAWT, resulting in increasing the moment of the turbine.

Taken together, the Reynolds number effect on the micro wind turbines is an inevitable exist, and the influence rule of each type of wind turbine is relatively straightforward. However, the research of Reynolds number effect on micro wind turbine is rather little, and the limited experiment data derived from different model wind turbines at different experimental conditions prohibits the qualitative and quantitative comparison among different types of micro wind turbine. In this study, three types of micro wind turbines with approximately the same aerodynamic dimensions have been tested experimentally in the same wind tunnel to determine performance differences at low Reynolds number condition.

\section{EXPERIMENTAL METHOdOLOGY}

\subsection{Test Model and Test Device}

The capability of self-startup is considerably important for micro wind turbines, especially for lifttype wind turbines, because the startup of micro wind turbines only relies on the aerodynamic torque generated by their blades, different from that of large scale wind turbines depending on auxiliary measures. The excessive pursuit of high power coefficient, regardless of self-startup, is meaningless for micro wind turbines. Therefore, the model lifttype wind turbines included HAWT and H-VAWT, of which the aerodynamic profiles are determined based on being capable of self-startup, the micro
HAWT has relative large pitch angle of $10^{\circ}$ and the H-VAWT has the solidity of 0.25 .

In order to better compare aerodynamic performance differences, all model wind turbines have approximately the same aerodynamic dimensions. The aerodynamic dimensions of model wind turbines are depicted in detail below. The S-VAWT (Fig. 1a) is composed of 2 semicircular buckets with the diameter of $230 \mathrm{~mm}$ and the bucket height of $800 \mathrm{~mm}$. The rotation diameter and the overlap of S-VAWT are $360 \mathrm{~mm}$ and $100 \mathrm{~mm}$, respectively. The H-VAWT (Fig. 1b) has rotation diameter of $600 \mathrm{~mm}$ and pitch angle of $0^{\circ}$, of which the straight blades of NACA 0018 airfoil profile is with equal span length of $600 \mathrm{~mm}$ and chord length of $100 \mathrm{~mm}$. The micro HAWT (Fig. 1c) has 3 blades of NACA 0018 airfoil profile. The straight blade is with equal chord length and no torsion, of which the blade length $L$ is $277 \mathrm{~mm}$, and the chord length $C$ is $50 \mathrm{~mm}$. The hub diameter $d$ is $46 \mathrm{~mm}$.

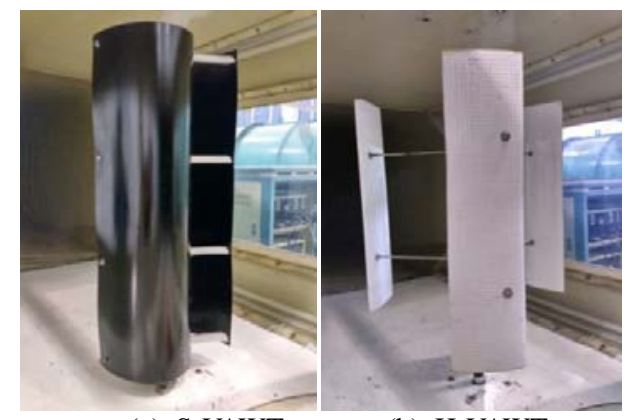

(a) S-VAWT

(b) H-VAWT

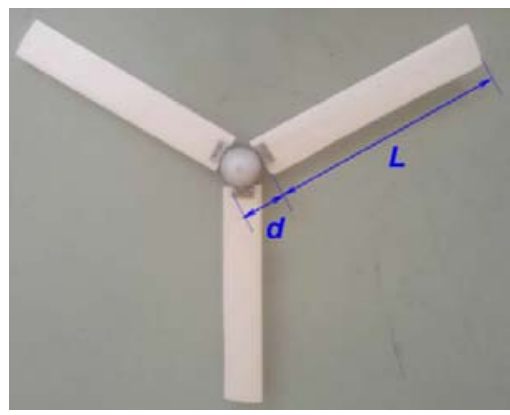

(c) HAWT

Fig. 1. Model wind turbines.

The experiment has been conducted in a low speed wind tunnel in Shenyang Aerospace University, as shown in Fig. 2, which has the working section of $1.2 \mathrm{~m}(\mathrm{~W}) \times 1.0 \mathrm{~m}(\mathrm{H}) \times 3 \mathrm{~m}(\mathrm{~L})$. The stably controllable wind speed ranges from $4 \mathrm{~m} / \mathrm{s}$ to $50 \mathrm{~m} / \mathrm{s}$ with the turbulence intensity less than $0.14 \%$. The blocking ratios of the HAWT, H-VAWT and SVAWT, referring to the ratios of the swept area of the wind turbines to the cross-sectional area of the test section, are $23.5 \%, 30 \%$, and $0.24 \%$, respectively.

Figure 3 shows the test device, of which the wind turbine, rotation speed and torque meter and electromagnetic brake are installed successively from upstream to downstream of the wind. The meter 
connected to the computer collects the rotation speed, torque and power with the sampling frequency of $10 \mathrm{~Hz}$. The electromagnetic brake adjusts the rotation speed by exerting load on the rotation axis. In the experiment, the torque measurement range is $3 \mathrm{Nm}$ with the accuracy of $0.3 \%$ (F.S), the speed measurement range is $6000 \mathrm{rpm}$ with the accuracy of $0.1 \%$, and the total friction torque of the testing device is less than $0.03 \mathrm{Nm}$. Figure 5 also shows the test case for HAWT, the test device is fixed horizontally on the bottom of the wind tunnel working section. As to VAWT, the test device is vertically positioned outside of the working section and connects to the rotation axis of VAWT.

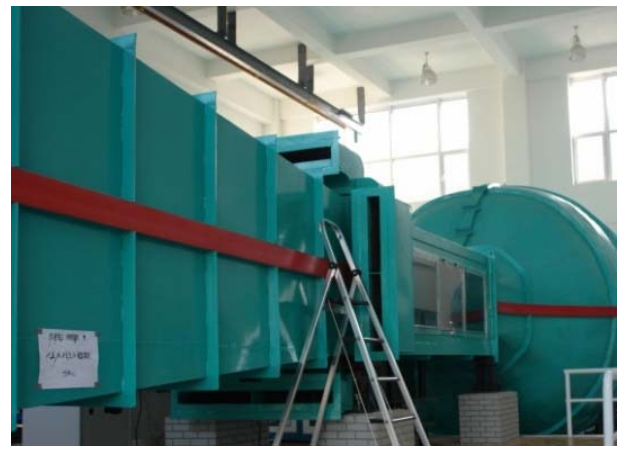

Fig. 2 Low speed wind tunnel in SAU.

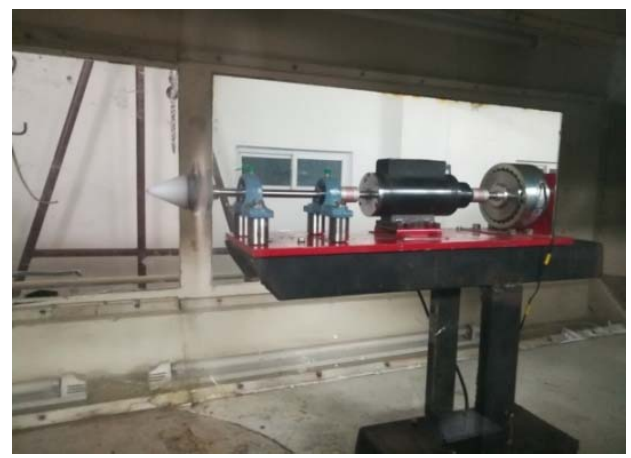

Fig. 3 Test device.

\subsection{Test Method and Content}

In addition to the performance comparison of different types of wind turbines, the effect of Reynolds number on the aerodynamic characteristics is also the emphasis of the research. As to HAWT and H-VAWT, the chord length is usually considered as characteristic length, while SVAWT is composed of 2 semicircular buckets. The three different wind turbines has almost aerodynamic dimensions, of which the rotation diameter is the most obvious characteristic length. Besides, the order of Reynolds number based on rotation diameter and oncoming wind speed is nearly consistent with that based on chord length and tip speed for HAWT and H-VAWT. In the experiment, different Reynolds Numbers were achieved by changing wind speed, varying from $5 \mathrm{~m} / \mathrm{s}$ to $13 \mathrm{~m} / \mathrm{s}$ corresponding to the Reynolds number order of $10^{5}$, based on rotation diameter and incoming wind speed. The minimum tested wind speed for certain type of wind turbine is based on being capable of self-startup and relatively significant power output.

In the test process, the wind turbine firstly starts and reaches the maximum rotation speed under no load, and then the rotation speed was changed by the electromagnetic brake loading, the torque and power of the wind turbine under different stable speed conditions are measured and collected.

The aerodynamic characteristics of wind turbines are usually represented by the relationship between power coefficient $C p$ and torque coefficient $C m$ with tip speed ratio $\lambda$. $C p$ is the ratio of the power $P$ to incoming wind energy in wind turbine swept area, representing the utilization efficiency of wind energy. $\mathrm{Cm}$ proportional to torque $M$ equals the ratio of $C p$ to $\lambda$, representing the load bearing capacity of the wind turbine. The tip speed ratio $\lambda$ is the ratio of tip speed of the turbine to wind speed $V_{\infty}$. They are defined as follows:

$$
\begin{aligned}
& P=M \omega=2 \pi n M / 60 \\
& C_{P}=2 P / \rho A V_{\infty}^{3} \\
& C_{m}=C_{P} / \lambda \\
& \lambda=\omega D / 2 V_{\infty}
\end{aligned}
$$

where $\omega(\mathrm{rad} / \mathrm{s})$ is the rotational angular velocity, $n$ (rpm) stands for the rotation speed, $\rho\left(\mathrm{kg} / \mathrm{m}^{3}\right)$ is air density, $A\left(\mathrm{~m}^{2}\right)$ is the swept area, which is calculated from $A=\pi D^{2} / 4$.

\section{RESULTS AND DISCUSSIONS}

\subsection{Comparison of Startup Characteristics}

Figures 4 and 5 show curves of power versus rotation speed and curves of torque coefficient versus tip speed ratio for three different model wind turbines, respectively. As shown in Fig. 4a, the power of S-VAWT is significantly obvious at $5 \mathrm{~m} / \mathrm{s}$, indicating that S-VAWT has natural advantage of start-up at low wind speed. The driving force of S-VAWT comes from pressure differences between concave side and convex side of semicircular buckets, the torque coefficient decrease linearly with tip speed ratio, as shown in Fig. 5a. The maximum torque coefficient is at low tip speed ratio corresponding to initial phase of startup, which is in favor of start-up.

As shown in Fig. 4b and Fig. 4c, there exists obvious power at $8 \mathrm{~m} / \mathrm{s}$ for H-VAWT and at $9 \mathrm{~m} / \mathrm{s}$ for HAWT, respectively. The startup wind speed is relatively higher for these two lift type wind turbines, this is because the extremely low Reynolds number and separation flow at large angle of attack degrade aerodynamic performance of airfoil. Figure 5 b shows the curve of torque coefficient versus tip speed ratio for H-VAWT, the torque coefficient increases first and then decreases with tip speed ratio. The relatively smaller torque coefficient is at low tip speed ratio, which is against startup. 


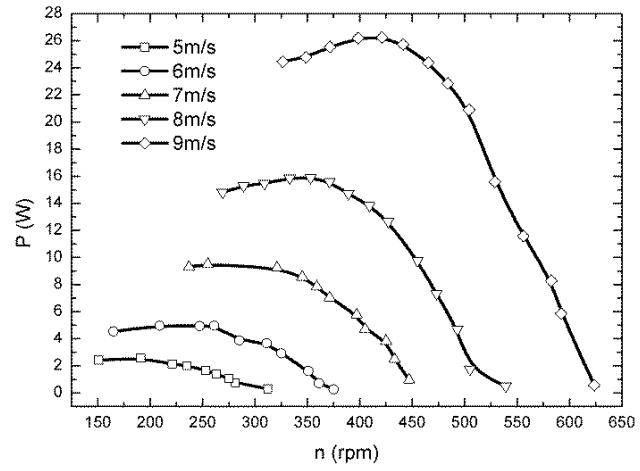

(a) S-VAWT

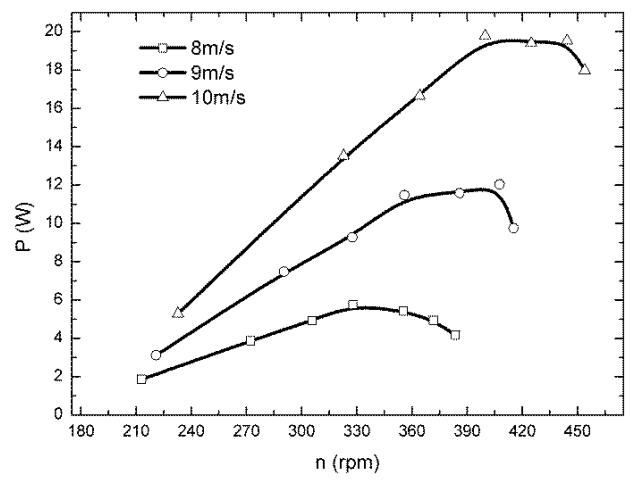

(b) H-VAWT

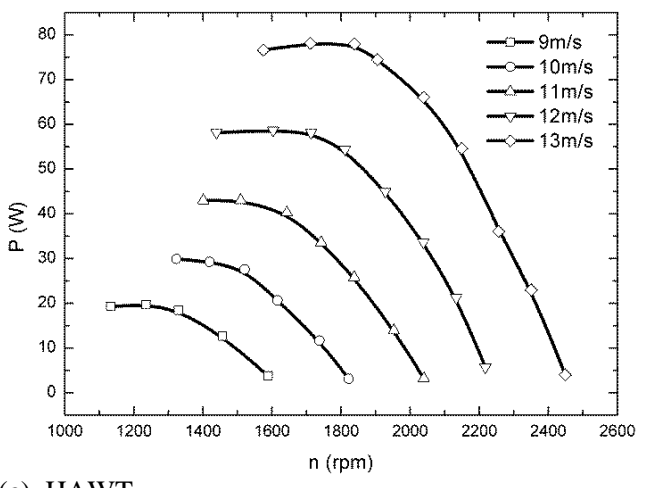

(c) HAWT

Fig. 4. Power versus rotation speed for model wind turbines.

\subsection{Comparison of Power and Rotation Speed}

As shown in Fig. 4, the power increases first and then decreases for three model wind turbines, in addition, the peak power and the corresponding rotation speed increase with wind speed. Under tested wind speeds, the rotation speeds for S-VAWT, H-VAWT and HAWT range from 150rpm to 550rpm, 210rpm to 450rpm and 1100rpm and 2500rpm, respectively. Under the same wind speed of $9 \mathrm{~m} / \mathrm{s}$, the rotation speed ranging from 1100rpm to 1600rpm for HAWT is much larger than that ranging from 210rpm to 400rpm for $\mathrm{H}$-VAWT, showing the advantage of vertical axis wind turbine in low operating rotation speed and low aerodynamic noise. In respect of power, the peak power of $20 \mathrm{~W}$ for HAWT is much higher than that of $12 \mathrm{~W}$ for H-VAWT at $9 \mathrm{~m} / \mathrm{s}$, though the swept area of HAWT is smaller. The higher rotation speed and the better aerodynamic performance of airfoil at higher Reynolds number due to higher rotation speed conspire to make the HAWT more efficient. It should be noted that the peak power of $26 \mathrm{~W}$ for $\mathrm{S}-\mathrm{VAWT}$ at $9 \mathrm{~m} / \mathrm{s}$ is higher than that for HAWT, therefore, S-VAWT has advantage in output power at low wind speed.

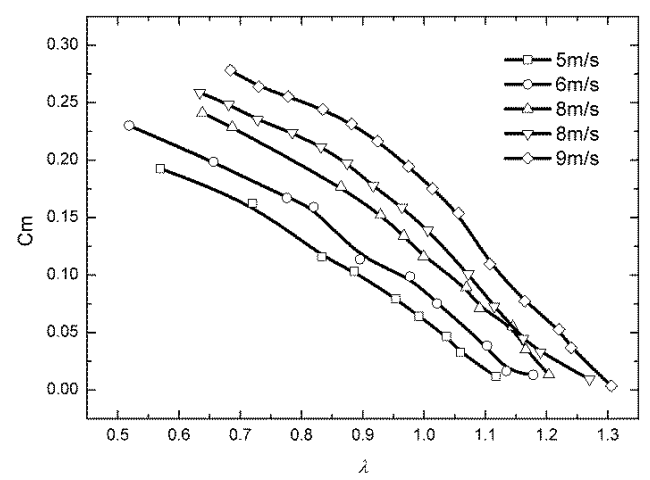

(a) S-VAWT

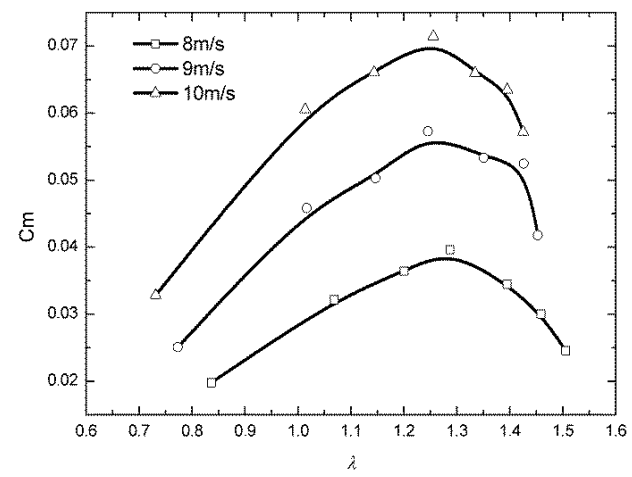

(b) H-VAWT

Fig. 5. Torque coefficient versus tip speed ratio for model wind turbines.

\subsection{Comparison of Power Coefficient and Tip Speed Ratio}

In order to further reveal aerodynamic performance differences among three different wind turbines, the relationship between power coefficient and tip speed ratio has been obtained based on Eqs. (2) and (4), as shown in Fig. 6. The power coefficient $C p$ increases first and then decreases for all wind turbines. The operating tip speed ratio $\lambda$ of S-VAWT ranges from 0.5 to 1.3 , and the tip speed ratio $\lambda$ corresponding to peak power coefficient ranges from 0.7 to 0.85 , less than 1, indicating that S-VAWT's work mainly relies on drag. Besides, the value of power coefficient $C p$ is positive at the tip speed ratio more than 1 , indicating that S-VAWT is not pure drag type wind turbine, the lift generated form convex side of semicircular bucket also contributes to output power. The operating tip speed ratio $\lambda$ of H-VAWT ranges from 0.7 to 1.5 , and the tip speed ratio $\lambda$ corresponding to peak power coefficient ranges from 
1.2 to 1.4. The operating tip speed ratio $\lambda$ of HAWT ranges from 3.8 to 5.9 , and the tip speed ratio $\lambda$ corresponding to peak power coefficient ranges from 3.8 to 4.4 . The tip speed ratio $\lambda$ corresponding to peak power coefficient of H-VAWT and HAWT is more than 1 , indicating that these two wind turbines' work mainly relies on lift. The tip speed ratio $\lambda$ corresponding to peak power coefficient of HAWT is much larger than that of H-VAWT, since the relatively large solidity is selected in consideration of start-up for H-VAWT. In aspect of peak power coefficient, though the peak power coefficient varies with wind speed, the peak power coefficients of different wind turbines can be compared at $9 \mathrm{~m} / \mathrm{s}$. The peak power coefficients for S-VAWT, HAWT and H-VAWT are $0.2,0.15$ and 0.07 , respectively, indicating that the aerodynamic performance of SVAWT is superior to that of HAWT, while $\mathrm{H}$ VAWT performs the worst.

\subsection{Reynolds Number Effect}

The Reynolds number effect on aerodynamic performance can also be seen in Fig. 6. For SVAWT, the peak power coefficient and the corresponding tip speed ratio increases with Reynolds number, which is consistent with research result of Sheldahl et al. (1978). It is also shown that $\mathrm{S}-\mathrm{VAWT}$ is not pure drag type wind turbine, the convex of the bucket generates suction and the Reynolds number affects the boundary layer of the convex. Faster wind speed and rotation speed cause higher Reynolds number, which leads to better performance at higher tip speed ratio. For H-VAWT, the peak power coefficient increases with Reynolds number, while higher peak power coefficient is obtained at lower tip speed ratio, which is consistent with research result of Somoano et al. (2018). For HAWT, the higher peak power coefficient is obtained at lower tip speed ratio with Reynolds number, which is consistent with research results of Driss et al. (2013) and Zhu et al. (2018). The aerodynamic characteristics of the rotor can be analyzed qualitatively based on the aerodynamic characteristics of the selected airfoil used for the rotor. The maximum lift-drag-ratio and the corresponding angle of attack of the airfoil determines $C p \max$ and $\lambda$ of the rotor, respectively. The higher maximum lift-drag-ratio contributes to higher $C p \max$, while the larger corresponding angle of attack leads to lower corresponding $\lambda$. The research results of different wind turbines in this paper are in line with earlier studies, showing that the experimental data in the article is responsible and reliable.

\section{CONCLUSION}

Three different types of small wind turbines, including S-VAWT, H-VAWT and HAWT, were tested in the low speed wind tunnel, revealing the aerodynamic differences among them.

As the lift type wind turbine, H-VAWT and HAWT have difficulty in self-startup, and of which the startup wind speed is relatively high. However, the maximum torque coefficient exists at initial start-up phase, which enable S-VAWT having natural advantage in self-startup capacity at low wind speed.

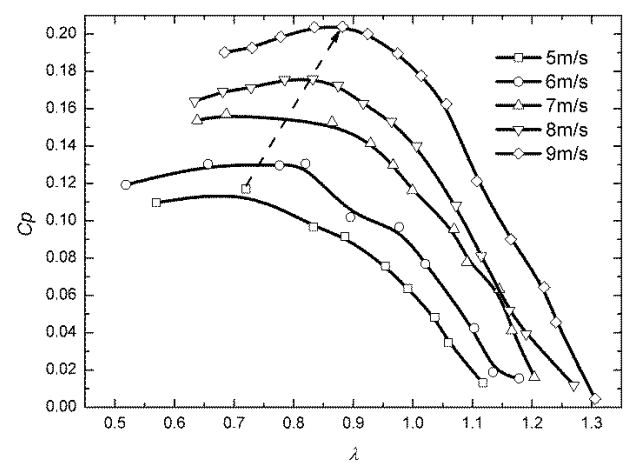

(a) S-VAWT

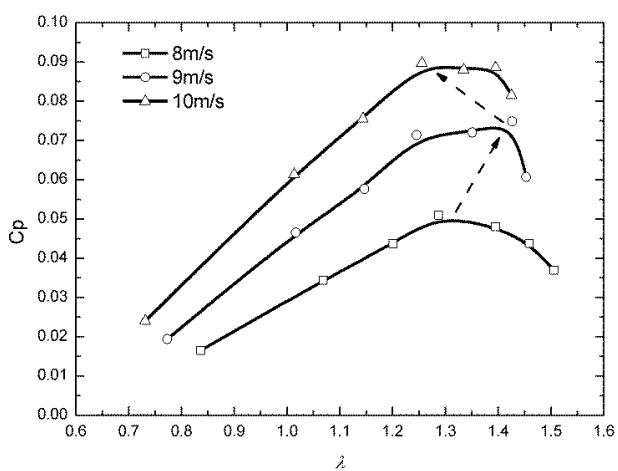

(b) H-VAWT

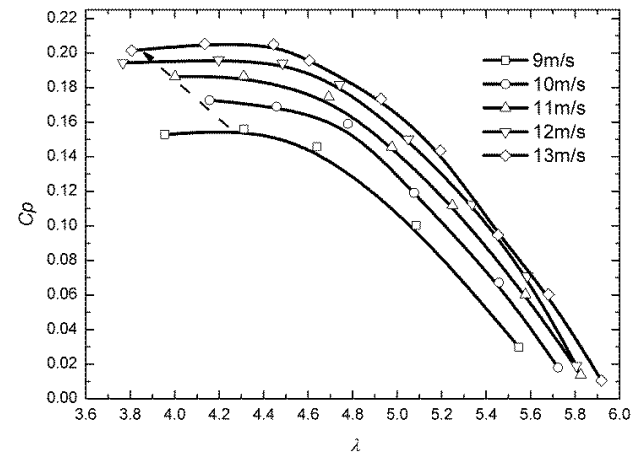

(c) HAWT

Fig. 6. Power coefficient versus tip speed ratio for model wind turbines.

As to aerodynamic characteristics, in the tested wind speed range, the power coefficient of three types of wind turbines is sensitive to Reynolds number, and the peak power coefficient increase with Reynolds number. The tip speed ratio corresponding to peak power coefficient for H-VAWT and HAWT of lift type wind turbine is greater than 1 , however, the deteriorative aerodynamic performance of airfoil at low Reynolds number makes the peak power coefficient relatively low at low wind speed, besides, H-VAWT with larger solidity has difficulty in operating at relatively higher rotation speed and the peak power coefficient of which is much lower than 
that of HAWT. The apparent output power for SVAWT can be obtained at low wind speed, with the peak power coefficient higher than that of other two lift typed wind turbines and the corresponding tip speed ratio ranging from 0.7 to 0.85 .

From the two aspects of self-startup capacity and aerodynamic performance, S-VAWT is the best option, applied at low Reynolds number environment.

\section{REFERENCES}

Akwa, J. V., H. A. Vielmo and A. P. Petry (2012). A review on the performance of Savonius wind turbines. Renewable and Sustainable Energy Reviews 16(5), 3054-3064.

Bhutta, M. M. A., N. Hayat, A. U. Farooq and Z. Ali (2012). Vertical axis wind turbine - A review of various configurations and design techniques. Renewable and Sustainable Energy Reviews 16(4), 1926-1939.

Dayan, E. (2006). Wind energy in buildings: Power generation from wind in the urban environment - where it is needed most. Refocus 7(2), 33-38.

Driss, Z., S. Karray, A. Damak and S. A. Mohamed (2013). Experimental Investigation of the Reynolds Number'S Effect on the Aerodynamic Characteristics of a Horizontal Axis Wind Turbine of the Gottingen 188 Airfoil Type[J]. American Journal of Mechanical Engineering 1(5), 143-148.

Gipe, P. (1999). Wind energy basics. Chelsea Green Publishing Company Vermont, Totnes, England.

Kang, C., H. Liu and X. Yang (2014). Review of fluid dynamics aspects of Savonius-rotor-based vertical-axis wind rotors. Renewable and Sustainable Energy Reviews 33, 499-508.
Karthikeyan, N., K. Kalidasa Murugavel, S. Arun Kumar and S. Rajakumar (2015). Review of aerodynamic developments on small horizontal axis wind turbine blade. Renewable and Sustainable Energy Reviews 42, 801-822.

Ledo, L., P. B. Kosasih and P. Cooper (2011). Roof mounting site analysis for micro-wind turbines. Renewable Energy 36(5), 1379-1391.

Mertens, S. (2002). Wind energy in urban areas: Concentrator effects for wind turbines close to buildings. Refocus 3(2), 22-24.

Peacock, A. D., D. Jenkins, M. Ahadzi, A. Berry and S. Turan (2008). Micro wind turbines in the UK domestic sector. Energy \& Buildings 40(7), 1324-1333.

Roy, S. and U. K. Saha (2013). Review on the numerical investigations into the design and development of Savonius wind rotors. Renewable and Sustainable Energy Reviews 24, 73-83.

Sheldahl, R. E., L. V. B. Feltz and B. F. Blackwell (1978). Wind tunnel performance data for twoand three-bucket Savonius rotors. Journal of Energy 2(3), 160-164.

Somoano, M. and F. Huera-Huarte (2018). The dead band in the performance of cross-flow turbines: Effects of Reynolds number and blade pitch. Energy conversion and management 172, 277284.

Zemamou, M., M. Aggour and A. Toumi (2017). Review of savonius wind turbine design and performance. Energy Procedia 141, 383-388.

Zhu, J. Y. and P. Q. Liu (2018). Effect of Pitch Angle and Reynolds Number on Aerodynamic Characteristics of a Small Horizontal Axis Wind Rotor. Journal of Applied Fluid Mechanics 11(3), 613-620. 